\title{
Hypoplastic left heart syndrome with anomalous circumflex artery arising from left pulmonary artery. A description of combined surgical and interventional cardiac treatment
}

\author{
Marcin Gładki, Tomasz Mroczek, Magdalena Czerżyńska, Aleksandra Morka, Julita Sacharczuk, Janusz H. Skalski \\ Department of Pediatric Cardiac Surgery, Jagiellonian University Medical College, Krakow, Poland
}

Adv Interv Cardiol 2018; 14, 3 (53): 314-315

DOI: https://doi.org/10.5114/aic.2018.78339

Hypoplastic left heart syndrome (HLHS) belongs to the group of congenital complex heart defects that are characterized by hypoplasia of the left heart and the aorta [1]. The described coronary anomaly (anomalous left coronary artery arising from the pulmonary artery (ALCAPA)) is relatively rare in the group of patients with HLHS [1-4].

We present case of an HLHS patient, who was subjected to a hybrid procedure at 25 days old. In the sixth month of life, the patient was readmitted for planned reconstruction of the aorta, joining the aorta and the pulmonary artery trunk and performing the Glenn operation with pulmonary arterioplasty and left pulmonary artery (LPA) stent implantation (bare-metal stent, $10 \times$ $17 \mathrm{~mm}$ ). On the first postoperative day, the child's status was critical, with a markedly decreased right ventricular systolic function (EF $=38 \%$ ) and intense generalized stress reaction. Urgent catheterization demonstrated the anomalous circumflex artery $(C x)$ arising from the distal segment of the LPA (ALCAPA, Figure $1 \mathrm{~A}$ ). Catheterization showed the persistent left superior vena cava (L-SVC) draining directly into the coronary sinus which was embolized by a vascular Amplatzer plug (Figure $1 \mathrm{~B}$ ).

A reoperation was necessary, consisting in grafting the Cx to the neo-aorta. In the postoperative period, the patient presented with numerous episodes of cardiac rhythm disturbances (supraventricular tachycardia). In view of the persisting low saturation values, i.e. oxygen saturation $\left(\mathrm{O}_{2}\right)$ of $60 \%$, arterial partial pressure of oxygen $\left(\mathrm{PaO}_{2}\right)$ of $28-30 \mathrm{~mm} \mathrm{Hg}$, and distal LPA narrowing (Figure $1 \mathrm{C}$ ), another catheterization was achieved on the $10^{\text {th }}$ day after surgery, during which LPA stent redilatation was performed (Figure 1 D).
After the procedure, oxygenation improved (sat. $\mathrm{O}_{2} 85 \%$; $\mathrm{PaO}_{2}$ 38-40 $\mathrm{mm} \mathrm{Hg}$ ) and the heart rhythm disturbances gradually resolved. The child was discharged home 14 days after stent implantation. At present, the 12-month old child is in a good general condition, presenting no signs of overt heart insufficiency. Her saturation is maintained at $\mathrm{O}_{2} 80 \%$ and $\mathrm{EF}$ in echocardiography is $50 \%$.

The available literature presents only a few descriptions of patients with HLHS and ALCAPA; in the vast majority of cases, such patients did not live beyond the first postoperative day [1, 2].

The first stage of HLHS treatment is a severe trauma for the child, and the surgery itself, as well as the duration of cardiopulmonary bypass, may be long [3]. Therefore, the probability of the patient developing coronary ischemia increases, especially in subjects with anomalies of the coronary arteries [4]. Thanks to interdisciplinary collaboration of cardiac surgeons, interventional cardiologists and echocardiographists, our patient successfully completed her surgical treatment and was discharged; at home, she is currently awaiting the next stage of treatment (Fontan procedure).

Coronary anomalies in the form of abnormal origin of the coronary vessels are very rare abnormalities in HLHS, and such abnormalities continue to pose a challenge for a cardiac surgical team. Careful observation of the patient after the first stage of surgery and before qualification for the next stage allows alarming episodes, e.g. desaturation, to be noted, in which case the diagnostic management should be extended.

\section{Conflict of interest}

The authors declare no conflict of interest.

\section{Corresponding author:}

Magdalena Czerżyńska MSc, Department of Pediatric Cardiac Surgery, Jagiellonian University Medical College, 265 Wielicka St, 30-663 Krakow, Poland, phone/fax: +48 501540 689, e-mail: mmagdalenacz@gmail.com

Received: 4.01.2018, accepted: 23.04.2018. 

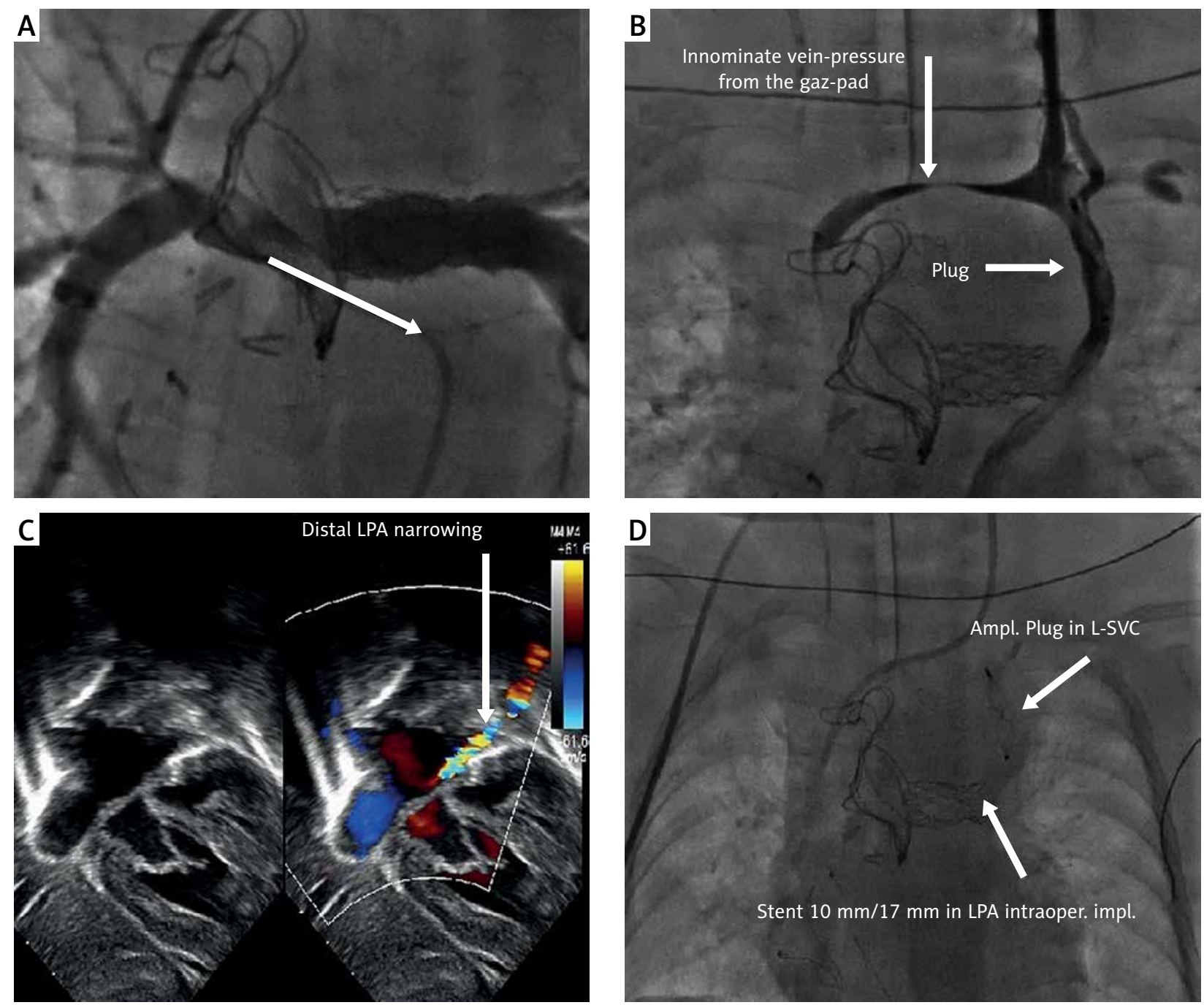

Figure 1. A - Postoperative heart catheterization showing anomalous circumflex artery arising from the distal segment of the left pulmonary artery. B - Postoperative heart catheterization demonstrated persistent left superior vena cava (L-SVC) Heart team (cardiologist, cardiac surgeon, intervention cardiologist) decided to embolize by vascular Amplatzer plug implantation. Catheterization was performed early after surgery. The patient had been still on open chest due to gaz-pad being illustrated on the radiogram. C - Transthoracic echocardiography demonstrated distal left pulmonary artery (LPA) stent narrowing with Doppler gradient 60-70 mm $\mathrm{Hg}$. D - Next catheterization procedures with LPA stent redilatation

\section{References}

1. Nathan M, Emani S, Marx G, et al. Anomalous left coronary artery arising from the pulmonary artery in hypoplastic left hearts: case series andreview of literature. J Thorac Cardiovasc Surg 2011; 142: 225-7.

2. Jaworski R, Kansy A, Łaniewski-Wołtk P. Anomalous origin of circumflex coronary artery from right pulmonary artery in a hypoplastic left heart syndrome child. Kardiochir Torakochir Pol 2014; 11: 210-2.

3. Nosál' M, Omeje IC, Poruban R. Hypoplastic left heart syndrome with anomalous origin of left coronary artery from the right pulmonary artery: successful surgical treatment in a neonate. Eur J Cardiothorac Surg 2005; 28: 497-8.

4. Cleuziou J, Haas F, Schreiber C, et al. Hypoplastic left heart syndrome with anomalous origin of the right coronary artery. Ann Thorac Surg 2006; 81: 341-3. 